\title{
Reorganização do modelo de atenção às pessoas vivendo com HIV: A experiência do município de Florianópolis/SC
}

\section{Reorganizing the patient care model for people living with HIV: The case of Florianópolis/SC \\ Reorganización del modelo de atención a personas que viven con VIH: La experiencia del municipio de Florianópolis/SC}

\author{
Vitor Menoita Pinto ${ }^{1}$, Nuno de Mattos Capeletti ${ }^{1} \mathbb{D}$ \\ ${ }^{1}$ Escola de Saúde Pública de Florianópolis. Florianópolis, SC, Brasil. \\ 2 Prefeitura Municipal de Florianópolis. Florianópolis, SC, Brasil.
}

\section{Resumo}

Introdução: O Médico de Família e Comunidade tem como função cuidar dos agravos mais comuns em seu território adstrito e coordenar o cuidado dos usuários. A infecção pelo vírus da imunodeficiêcia humana, por ser uma condição comum em várias populações e comunidades, deve ser uma doença de interesse deste profissional. Métodos: Trata-se de estudo descritivo, relato de experiência, vivenciado por preceptor e residente no município de Florianópolis. Resultados: $O$ presente artigo pretende discutir a reorganização do atendimento às pessoas vivendo com o vírus e a importância da atenção primária na aplicação de diferentes abordagens preventivas e na construção da meta 90-90-90. Conclusão: A busca da descentralização no cuidado desta população mostra-se como uma grande potencialidade local para o cumprimento do objetivo de melhorar os indicadores de controle da doença, destacando-se fatores locais como a rede de atenção primária estruturada, a gestão eficiente e a busca da qualificação profissional.

Palavras-chave: Atenção Primária à Saúde; HIV; Médicos de Família

\begin{abstract}
Introduction: The Family Physician is responsible for coordinating and providing care to address the most common diseases in a particular territory. Given that the Human Immunodeficiency Virus infection affects various segments of the population, this professional should be aware about the issue. Methods: This is a descriptive report based on what the resident and his/her tutor experienced in Florianópolis. Results: The article discusses the reorganization of the patient care model in order to serve people living with the virus. It also explores the importance of Primary Health Care strategies adopted by the city government in order to use different preventive approaches and build $90-90-90$ treatment targets. Conclusion: The decentralization in this population health care appear to be a local potentiality to improve the disease control, mainly because of the structured primary care, efficient management and search of professional qualification.
\end{abstract}

Keywords: Primary Health Care; HIV; Physicians, Family

Como citar: Pinto VM, Capeletti NM. Reorganização do modelo de atenção às pessoas vivendo com HIV: A experiência do município de Florianópolis/SC. Rev Bras Med Fam Comunidade. 2019;14(41):1710. https://doi.org/10.5712/rbmfc14(41)1710
Autor correspondente: Vitor Menoita Pinto. E-mail: menoitapi@gmail.com Fonte de financiamento: declaram não haver. Parecer CEP: não se aplica.

Procedência e revisão por pares: revisado por pares. Recebido em: 28/02/2018. Aprovado em: 22/02/2019. 


\section{Resumen}

Introducción: El Médico de Familia y Comunidad tiene como función cuidar de las enfermedades más comunes en su territorio y coordinar el cuidado ofrecido a los usuarios del sistema de salud. La infección por el virus de la inmunodeficiencia humana, por ser común en varias poblaciones y comunidades, debe ser una condición de interés para este profesional. Método: Esta publicación es una descripción basada en relato de la experiencia vivida por el preceptor y su residente en la ciudad de Florianópolis. Resultados: El presente artículo pretende discutir la reorganización de la atención a las personas que viven con el vírus y la importancia de la reorganización centrada en la Atencíon Pimaria de Salud para crear estrategias con diferentes enfoques preventivos y construir la meta 90-90-90. Conclusão: La descentralización del cuidado de esta población se muestra como una gran potencialidad local para cumplir el objetivo de mejorar los indicadores de control de la infección, resaltándose los fatores locales como la atención primaria organizada, la gestión eficiente y la búsqueda por la calificación profesional.

Palabras clave: Atención Primaria de Salud; VIH; Médicos de Familia

\section{Introdução}

A síndrome da imunodeficiência humana é causada por um retrovírus que infecta principalmente os linfócitos T CD4+ e é transmitido por via sexual, vertical (gestação, parto ou amamentação) e sanguínea (transfusão de sangue, compartilhamento de seringas ou acidentes perfuro cortantes). ${ }^{1,2}$ No Brasil, estima-se que $0,4 \%$ da população geral esteja contaminada com o HIV (830 mil pessoas). ${ }^{3}$

Atualmente, com a evolução dos antirretrovirais, a grande maioria dos pacientes em terapia antirretroviral (TARV) (80\%) apresentam supressão viral após um ano de tratamento. ${ }^{4}$ Novos estudos têm mostrado que as pessoas vivendo com HIV (PVHIV) com boa aderência e carga viral indetectável há pelo menos seis meses têm um risco considerado insignificante de transmitir o vírus (indetectável = intransmissível) por via sexual, contribuindo para a interrupção da epidemia e melhorando a qualidade de vida dessas pessoas. .,6 $^{5}$

Em 2013, o Programa Conjunto das Nações Unidas sobre HIVIAIDS definiu uma meta tríplice para o controle do HIV, conhecida como 90-90-90 e que consiste em: $90 \%$ de todas as pessoas vivendo com HIV diagnosticadas (ampliando o acesso ao diagnóstico do HIV), 90\% dos HIV+ diagnosticados em tratamento antirretroviral (ampliando o acesso à TARV) e 90\% dos pacientes tratados com carga viral indetectável (indicando boa adesão ao tratamento). O prazo para o cumprimento da meta é o ano de $2020 .^{7}$

A grande evolução nos esquemas de TARV nos últimos anos mudou o prognóstico das PVHIV. Essa grande evolução, somada a outros fatores que são do escopo desse artigo, levaram o Ministério da Saúde a propor a reorganização do modelo de atenção às PVHIV. ${ }^{2}$ A Atenção Primária à Saúde (APS) tem papel fundamental nesse processo e pode ser determinante para atingir a meta 90-90-90. O presente artigo pretende discutir a reorganização do modelo de atenção às PVHIV focado na APS e os seus desafios através do relato da experiência no município de Florianópolis/SC.

\section{Métodos}

Trata-se de estudo descritivo, relato de experiência, vivenciado por preceptor e residente do segundo ano do Programa de Residência em Medicina de Família e Comunidade da Secretaria Municipal de Saúde de Florianópolis/SC durante o ano de 2017 e início de 2018. Tal observação é correlacionada com as práticas de controle do HIV descritas na literatura. 


\section{O processo de reorganização}

No início da epidemia de HIV, nos anos 1980, o modelo de atendimento para a PVHIV se centralizou em serviços especializados. Isso ocorreu em grande parte pela grande letalidade inicial da doença, dificuldade de seu manejo e desenvolvimento incipiente da atenção primária no Brasil. No início da década de 80, o Sistema Único de Saúde (SUS) ainda não existia e a Estratégia de Saúde da Família (ESF) só foi criada em 1994.

Apenas com os avanços no manejo do HIV e a consolidação da ESF nas décadas de 2000 e 2010 pode-se propor uma reorganização no modelo de atenção às PVHIV. Essa reorganização ocorreu e ocorre de formas diferentes no Brasil dependendo de vários fatores, a saber: organização da atenção primária nos municípios, articulação dos gestores locais, capacitação dos profissionais, pactuação com serviços de atenção especializada e adesão da população ao modelo de reorganização proposto. 8,9 $^{8,9}$

A reorganização do modelo de atenção em saúde para as PVHIV foi proposta pelo Ministério da Saúde tendo em vista o avanço nos cuidados dessa população nos últimos anos, a simplificação do esquema retroviral, a percepção do HIV como condição crônica e o aumento do número de PVHIV. Assim, atualmente, o manejo ambulatorial do HIV reúne muitas semelhanças ao tratamento de algumas doenças crônicas não transmissíveis, como a dificuldade de adesão ao tratamento medicamentoso e períodos de recaída, com agudização da doença. ${ }^{1,2} \mathrm{~A}$ ideia proposta é que diferentes níveis de atenção participem em diferentes momentos da linha de cuidado dessa população. 9,10

O Currículo Baseado em Competências para Medicina de Família e Comunidade orienta como competência essencial o diagnóstico e referenciamento adequado do paciente com HIV, bem como o manejo de problemas de adesão ao tratamento. O documento coloca como competência desejável o manejo de HIVIAIDS em pacientes sob os cuidados do médico de família. ${ }^{9,11}$

A atenção primária tem protagonismo nesse cenário, sempre tendo em vista o trabalho integrado e em rede com todos os níveis atenção à saúde. Os seus atributos essenciais (primeiro contato, longitudinalidade, integralidade e coordenação) e derivados (orientação familiar, orientação comunitária e competência cultural) tornam a APS uma frente de combate importante contra o HIV. AAPS pode contribuir em cada um dos itens da meta 90-90-90 de forma significativa, sendo destaque: ampliação dos pontos da rede de teste rápido (impacto na meta 1), busca ativa de pacientes pouco aderentes (impacto na meta 2) e ferramentas para melhorar a adesão ao tratamento (impacto meta na 3).9,12

Uma das tarefas do processo de reorganização consiste em selecionar quais pacientes são candidatos ao manejo na atenção primária. O Ministério da Saúde sugere, de forma geral, que pacientes assintomáticos estáveis podem ser acompanhados na APS. ${ }^{1,2,4}$

Em 2014, o Departamento de DST, AIDS e Hepatites virais publicou uma série de casos de descentralização do cuidado das PVIHIV em algumas capitais brasileiras: Curitiba, Porto Alegre, Rio de Janeiro e Fortaleza. O objetivo da publicação era mostrar como a reorganização e o manejo do HIV aconteciam na prática da atenção primária, expondo assim as fortalezas e limitações desse processo. ${ }^{13}$ 


\section{Resultados}

\section{A experiência de Florianópolis}

A estimativa de PVHIV residindo no município de Florianópolis é de 7884 pessoas ( $1,2 \%$ da população). Calcula-se que aproximadamente 1000 dessas pessoas não sabem do seu diagnóstico ( $13 \%$ do total de infectados). $\mathrm{O}$ desconhecimento do status sorológico tem impacto direto na manutenção da epidemia do HIV na cidade e é causa importante a ser trabalhada pelos profissionais de saúde. Quase a totalidade das pessoas diagnosticadas com HIV em Florianópolis estão vinculadas ao cuidado (realizaram exames ou retiraram medicamentos em 2016) e pouco mais da metade são consideradas retidas no cuidado (realizaram dois exames de carga viral ou receberam TARV nos últimos 100 dias). De todos os diagnosticados (6859 pessoas), 68\% estão em uso de TARV (4701 pessoas), e apenas 327 pacientes em uso de TARV não atingiram a supressão viral (carga viral inferior a 1000 cópias por $\mathrm{mm}^{3}$ ).

Chamam a atenção nesses dados a diferença de $21 \%$ entre PVHIV diagnosticadas e retidas no cuidado e a quantidade pouco maior que a metade (64\%) de pessoas com carga viral suprimida em relação às PVHIV diagnosticadas na cidade (6859 pessoas). Ou seja, 2485 pessoas diagnosticadas não estão com carga viral suprimida ( $36 \%$ do total de diagnosticados), conforme ilustrado nos Gráficos 1 e $2 .{ }^{14}$

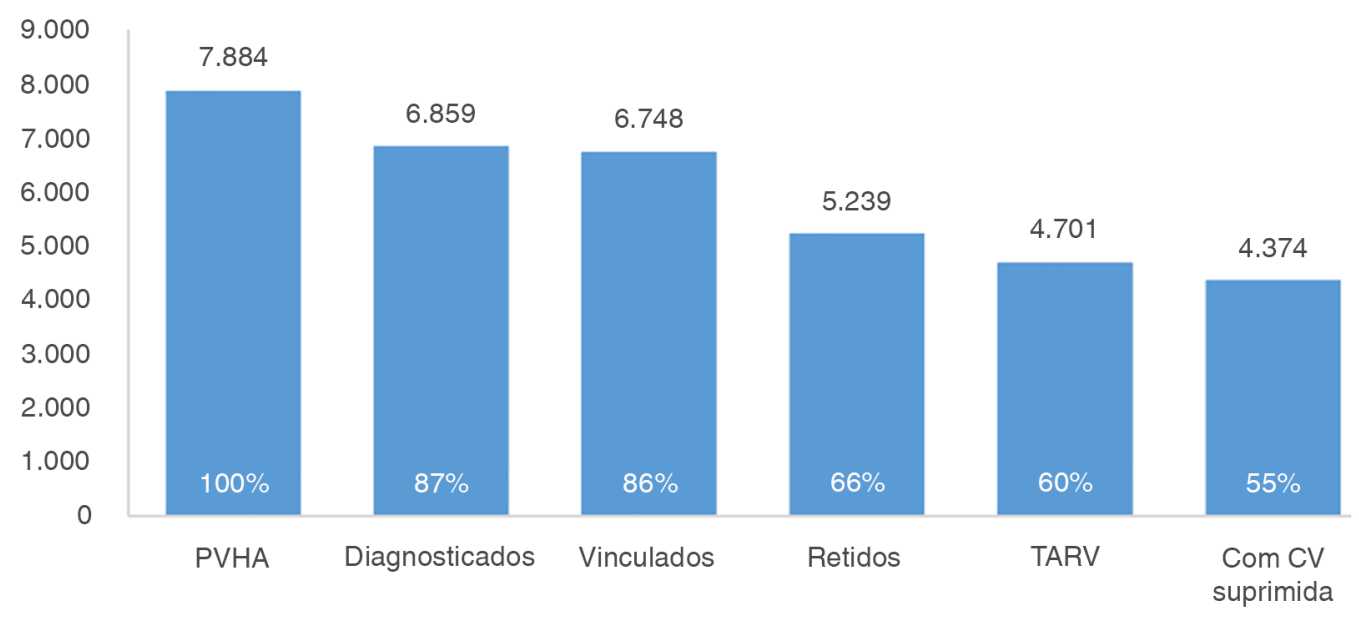

Gráfico 1. Cascata do cuidado do HIV em Florianópolis, 2017.

PVHA: pessoas vivendo com HIV/AIDS; TARV: terapia antirretroviral; CV: carga viral.

Fonte: Florianópolis, 2017.

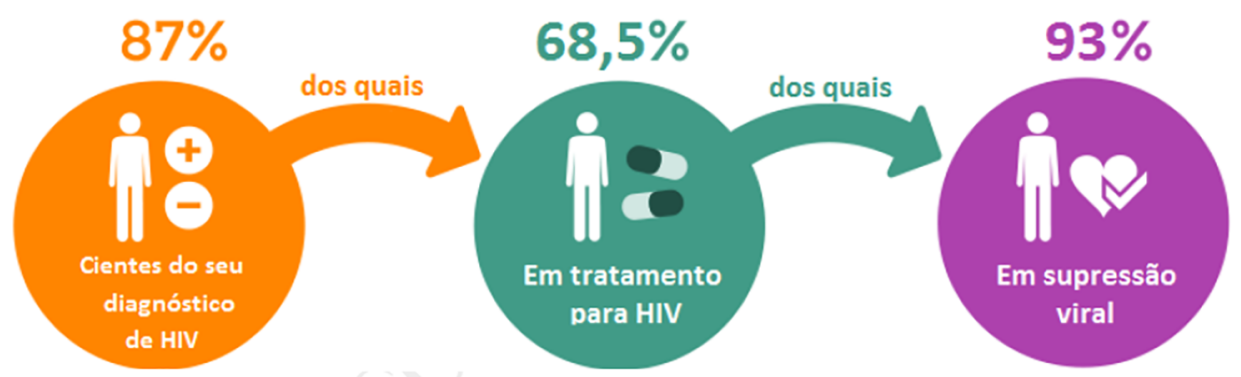

Gráfico 2. Meta 90-90-90 em Florianópolis. Fonte: Florianópolis, 2017. 
O processo de reorganização do atendimento às PVHIV em Florianópolis teve início em 2015 e atualmente envolve os 49 Centros de Saúde, 4 Policlínicas e 2 Unidades de Pronto Atendimento (UPAs) do município, além de laboratórios e hospitais estaduais e federais. ${ }^{15-17}$

Em 2015, a Secretaria Municipal de Saúde de Florianópolis implantou o Protocolo de Acesso à Infectologia e iniciou a elaboração do Apoio Matricial Regulado de Infectologia. Essa ferramenta visava dar suporte e criar um canal de comunicação direto entre as equipes de ESF e os infectologistas da rede de saúde municipal. O projeto possuía os seguintes objetivos: qualificar o acesso dos usuários encaminhados à Infectologia, ampliar a resolutividade da atenção primária, melhorar a articulação entre os profissionais da APS e os especialistas, além de descentralizar o tratamento, o acompanhamento e a profilaxia pós exposição ao HIV (PEP) para a APS. ${ }^{15-17}$

Diferentemente do Protocolo de Acesso à Infectologia, que tem a intenção de ser seguido desde sua implantação por todos os pontos da rede municipal de saúde, o Apoio Matricial começou como um projeto piloto e inicialmente abrangia apenas ESFs cujos médicos (dentre os quais fizemos parte) se sentiam capacitados e se mostraram dispostos a assumir o cuidado de PVHIV de forma compartilhada com os médicos infectologistas. Muitos dos médicos interessados eram vinculados ao programa de residência em Medicina de Família e Comunidade (MFC) do município. ${ }^{15-17}$

Inicialmente, a equipe de infectologistas se dividiu para atender às dúvidas de cada distrito sanitário da cidade. Os MFCs participantes do projeto podiam mandar as dúvidas dos casos que estavam conduzindo e esta comunicação era realizada exclusivamente pelo email da ESF endereçado para o email do apoio matricial. Atualmente, o matriciamento de infectologia encontra-se inativo e o apoio matricial ocorre pelo grupo de discussão via WhatsApp ${ }^{\circledR}$ com a presença de profissionais de diferentes áreas com afinidade pelo tema. Os principais motivos para o desligamento da ferramenta são divergências por parte dos infectologistas em relação ao cuidado compartilhado dos pacientes e falta de perfil matriciador. Isso ocorre em oposição à expansão dos apoios matriciais e protocolos de acesso no município. ${ }^{15-17}$

Em relação ao estímulo à capacitação profissional, um grande marco para a descentralização do atendimento a PVHIV em Florianópolis foi a implementação do Practical Approach to Care Kit (PACK Brasil Adulto) em julho de 2016. O PACK é uma ferramenta de apoio e um guia para médicos e enfermeiros de atenção primária que visa facilitar a tradução do conhecimento científico para a prática clínica, com importante adaptação dos fluxos apresentados à realidade local.

O PACK dedica cinco páginas para abordagem do HIV, dividida em: "HIV: diagnóstico" e "HIV: cuidados de rotina". Na primeira parte são abordados desde o incentivo para realizar a testagem, passando pelas possibilidades de resultados, até o suporte e aconselhamento pós-teste. Na segunda parte há maior detalhamento das indicações e opções de tratamento, além de fornecimento de informações práticas sobre como iniciar as medicações, seus efeitos colaterais mais comuns e cuidados de rotina. ${ }^{17,18}$

Já no que diz respeito ao atendimento para PEP no município de Florianópolis, este é disponibilizado nos 49 Centros de Saúde da cidade durante a semana, preferencialmente das $8 \mathrm{~h} 00$ às $10 \mathrm{~h} 30$ e das $13 \mathrm{~h} 00$ às 15h30. Nos finais de semana, feriados e das $16 \mathrm{~h} 00$ às $7 \mathrm{~h} 00 \mathrm{o}$ atendimento deve ocorrer preferencialmente nas duas UPAs (Sul e Norte). A dispensação dos antirretrovirais da PEP acontece na Unidade Dispensadora de Medicamentos (UDM) localizada no centro da cidade. ${ }^{17,18}$ 
Inicialmente, 11 Unidades da Federação receberam a profilaxia pré-exposição ao HIV (PrEP), distribuídas em 22 cidades e 35 serviços de saúde. Em Santa Catarina, apenas Florianópolis recebeu a PrEP em um primeiro momento. Os medicamentos foram dispensados no Centro de Testagem e Aconselhamento, localizado na Policlínica Centro. Inicialmente, as pessoas tiveram acesso à PrEP apenas por meio de ambulatório específico para a profilaxia. O ambulatório PrEP iniciou de suas atividades em janeiro de 2018 no próprio centro de testagem e está sendo conduzido por MFCs juntamente com a equipe local. ${ }^{4}$

Outro ponto importante recai sobre a publicização dos esforços do município no combate ao HIV. Neste sentido, a campanha "Pare o HIV em Floripa 2020", lançada em $1^{\circ}$ de dezembro de 2017 (dia mundial de luta contra a AIDS) tem como objetivo atingir a meta 90-90-90 até o ano de 2020. Assim, várias estratégias foram e serão postas em prática para "parar" a epidemia de HIV em Florianópolis (Quadro 1). Por fim, a própria reorganização do atendimento a essa população com a capilarização dos locais de atendimento impacta na transmissão do HIV. ${ }^{15-17,19}$

Quadro 1. Fortalezas do sistema público de saúde de Florianópolis que auxiliam no combate ao HIV.

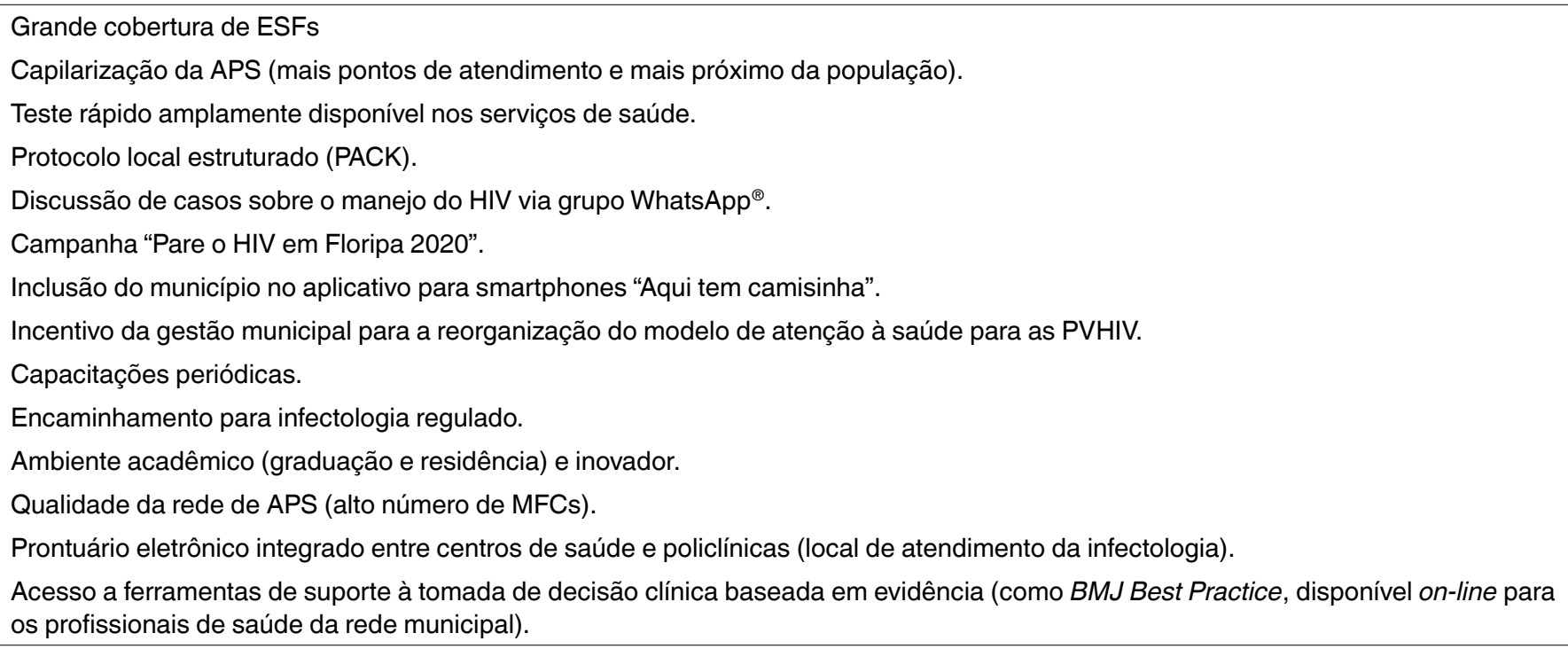

Fonte: Visão dos autores sobre a rede de APS de Florianópolis.

Outra estratégia importante, lançada com a campanha, foi a inclusão do município de Florianópolis no aplicativo "Aqui tem camisinha" para smartphones. A ferramenta é gratuita e começou no Brasil no carnaval de 2017. Através do georreferenciamento, o aplicativo apresenta os locais onde o usuário pode encontrar preservativos (gratuitos e pagos), testagem, tratamento e PEP na cidade. Além disso, o aplicativo explica como usar o preservativo masculino e feminino, qual conduta tomar caso a "camisinha estoure" (procurar unidade de saúde com PEP) e presta informações sobre ISTs. Ferramentas como essa emponderam as pessoas do seu cuidado e conectam o sistema de saúde ao usuário do SUS através de tecnologias cada vez mais importantes para o enfrentamento da epidemia de HIVIAIDS. ${ }^{19}$

A cidade de Florianópolis é reconhecida como uma das capitais com maior cobertura da ESF e conta com residência de MFC e multiprofissional totalmente integrada à rede de saúde. Com a ampliação do acesso à informação, preservativos, teste, PEP e ao tratamento, mais pessoas podem se proteger, ter 
acesso ao seu status sorológico e iniciar a PEP, tratamento ou PrEP. O acesso em demanda espontânea que a atenção primária tradicionalmente proporciona, próximo à residência da pessoa e com equipe multidisciplinar focada no atendimento integral ao indivíduo, a tornam um local atrativo para o acolhimento do universo HIVIAIDS.

\section{Conclusão}

O MFC deve estar atento para os desafios e as particularidades do acompanhamento das PVHIV, da consolidação da PEP e da implantação da PrEP. A capacitação continuada, a integração entre os membros da ESF e o suporte de toda a rede de cuidado às PVHIV são fundamentais para que o manejo do HIV na atenção primária funcione.

A meta 90-90-90 muito provavelmente só será atingida se todos os níveis de saúde e toda sociedade se comprometerem na luta contra o HIV. Dessa forma, são de suma importância o envolvimento e comprometimento de diversos atores no enfrentamento ao HIV: órgãos governamentais, universidades, gestores locais, profissionais de saúde, PVHIV, pessoas que se expuseram ao vírus e pessoas com risco aumentado de contrair o vírus.

A reorganização do modelo de atenção às PVHIV com foco na APS é um processo dinâmico e que envolve vários fatores. O contexto local da APS em cada município é fator importante nesse processo.

Em Florianópolis, a reorganização teve início recentemente e destacam-se como fortalezas a rede de atenção primária estruturada, a gestão qualificada e a busca da qualificação profissional. Em contraponto, também é preciso apontar como metas a diminuição do número de pessoas que desconhecem o seu status sorológico, o aumento da porcentagem de carga viral indetectável e o incremendo no número de infectologistas com perfil matriciador.

Assim, a cidade demonstra potencial para ser um exemplo importante de experiência na descentralização do cuidado dessa população e estar preparada para superar os desafios que o novo modelo de atendimento às PVHIV impõe na prática do SUS.

\section{Conflito de interesses}

Declaram não haver.

\section{Contribuição dos autores}

Concepção e/ou delineamento do estudo: VM, NM. Aquisição, análise ou interpretação dos dados: VM, NM. Redação preliminar: VM. Revisão crítica da versão preliminar: VM, NM. Todos os autores aprovaram a versão final e concordaram com prestar contas sobre todos os aspectos do trabalho.

\section{Agradecimentos}

Agradecemos à Residência de Medicina de Família e Comunidade da Escola de Saúde Pública de Florianópolis pela oportunidade de vivenciar o processo de reorganização do modelo de atenção às PVHIV na atenção primária de Florianópolis, referência nacional de qualidade e inovação. 


\section{Referências}

1. Brasil. Ministério da Saúde. Secretaria de Vigilância em Saúde. Cuidado integral às pessoas que vivem com HIV pela Atenção Básica - Manual para a equipe multiprofissional. 2015. Brasília: Ministério da Saúde; 2015.

2. Brasil. Ministério da Saúde. Secretaria de Vigilância em Saúde. O Manejo da Infecção pelo HIV na Atenção Básica - Manual para Profissionais Médicos. 2015. Brasília: Ministério da Saúde; 2015.

3. Brasil. Ministério da Saúde. Secretaria de Vigilância em Saúde. Protocolo Clínico e Diretrizes Terapêuticas para Profilaxia Pré-Exposição (PrEP) de Risco à Infecção pelo HIV Versão Preliminar. Brasília: Ministério da Saúde; 2017.

4. Brasil. Ministério da Saúde. Secretaria de Vigilância em Saúde. Protocolo clínico e diretrizes terapêuticas para manejo da infecção pelo HIV em adultos. 2017. Brasília: Ministério da Saúde; 2017.

5. Messaging Primer \& Consensus Statement. Risk of sexual transmission of HIV from a person living with HIV who has an undetectable viral load. 2017.

6. $U=U$ taking off in 2017. Lancet HIV. 2017;4(11):e475.

7. UNAIDS. 90-90-90 Uma meta ambiciosa de tratamento para contribuir para o fim da epidemia de AIDS. 2015. [acesso 2017 Nov 29]. Disponível em: https://unaids.org.br/wp-content/uploads/2015/11/2015_11_20_UNAIDS_TRATAMENTO_META_PT_v4_GB.pdf

8. Zambenedetti G, Silva RAN. Descentralização da atenção em HIV-Aids para a atenção básica: tensões e potencialidades. Physis Rev Saúde Coletiva. 2016;26(3):785-806. https://doi.org/10.1590/s0103-73312016000300005

9. Brasil. Ministério da Saúde. Secretaria de Vigilância em Saúde. HIV/AIDS na Atenção Básica: Material para Profissionais de Saúde e Gestores. 2017. Brasília: Ministério da Saúde; 2017.

10. Brasil. Ministério da Saúde. 5 passos para a implementação do manejo da infecção pelo HIV na Atenção Básica - Manual para gestores. 2014. Brasília: Ministério da Saúde; 2014.

11. Sociedade Brasileira de Medicina de Família e Comunidade - SBMFC. Currículo Baseado em Competências para Medicina de Família e Comunidade;2014. [acesso 2017 Dez 10]. Disponível em: https://www.sbmfc.org.br/wp-ontent/uploads/media/Curriculo\%20Baseado\%20 em\%20Competencias(1).pdf

12. Starfield B. Atenção primária: equilíbrio entre necessidades de saúde, serviços e tecnologia. Brasília: UNESCO, Ministério da Saúde; 2002.

13. Brasil. Ministério da Saúde. Secretaria de Vigilância em Saúde. Caderno de boas práticas em HIV/AIDS na Atenção Básica. 2014. Brasília: Ministério da Saúde; 2014.

14. Florianópolis. Secretaria Municipal de Saúde. Vigilância em Saúde. Boletim Epidemiológico número 3 de Dezembro de 2016. HIV/AIDS em Florianópolis - Cascata 90/90/90. 2017.

15. Florianópolis. Secretaria Municipal de Saúde. Diretoria de Atenção à Saúde. Apoio Matricial Regulado da Infectologia - Projeto Piloto de Apoio Matricial Regulado da Infectologia. 2017.

16. Florianópolis. Secretaria Municipal de Saúde. Diretoria de Atenção à Saúde. Critérios de Alta Ambulatorial de PVHA para o - Projeto Piloto de Apoio Matricial Regulado da Infectologia. 2017.

17. Florianópolis. Secretaria Municipal de Saúde. Diretoria de Atenção à Saúde. Protocolo de Acesso Infectologia. 2017.

18. Fair A. PACK Brasil Adulto. Kit de Cuidados em Atenção Primária. Ferramenta de manejo clínico em Atenção Primária à Saúde. Cape Town: University of Cape Town Lung Institute's Knowledge Translation Unit; 2017.

19. Florianópolis lança campanha para zerar transmissão de HIV [acessado em: 30 dez 2017]. Disponível em http://www.pmf.sc.gov.br/ entidades/saude/?pagina=notpagina\&menu=\&noti=19147. 